\title{
Age at menarche and adult height in girls born small for gestational age
}

\author{
Young Suk Shim, MD', \\ Hong Kyu Park, MD², \\ Seung Yang, $\mathrm{MD}, \mathrm{PhD}^{3}$, \\ II Tae Hwang, MD, PhD ${ }^{3}$ \\ ${ }^{1}$ Department of Pediatrics, Ajou \\ University Hospital, Ajou University \\ School of Medicine, Suwon, \\ 2Department of Pediatrics, Hallym \\ University Dongtan Sacred Heart \\ Hospital, Hwaseong, ${ }^{3}$ Department \\ of Pediatrics, Hallym University \\ Kangdong Sacred Heart Hospital, \\ Seoul, Korea
}

Purpose: The aim of this study was to evaluate the association between birth characteristics based on birth weight for gestational age, timing of menarche and adult height in girls born small for gestational age (SGA).

Methods: Thirty subjects born from 1988 through 1999 whose birth weight below 10th percentile for their gestational ages were recruited based on hospital chart reviews. The age of each subject at menarche was recorded, and the subject's heights and bone age were assessed.

Results: The adult height of the girls born SGA was significantly lower than the normal adult height and slightly shorter than their target height. The adult height was associated with the birth weight for gestational age. The age at menarche was not different with the menarche timing of the general population.

Conclusion: More attention may need to be paid to the growth outcomes of SGA patients whose birth weight is lower for their gestational age than other SGA subjects.

Keywords: Small for gestational age infant, Menarche, Body height

\section{Introduction}

Small for gestational age (SGA) is defined as a birth weight and/or length below the 10th percentile for gestational age ${ }^{1)}$. Many underlying factors have been suggested to cause intrauterine growth restriction.

A previous study reported that SGA girls began menarche approximately 5 months earlier than normal girls ${ }^{2}$. Another study ${ }^{3)}$ reported that girls who were long and light at birth tended to begin menarche earlier than those who were short and light. Faster growth in the first 6 months of life was also reported to be significantly correlated with earlier age at menarche ${ }^{4)}$

The risk for short stature in later life was found to be 5- to 7-fold higher in subjects born $\mathrm{SGA}^{5,6)}$, with approximately $6-10 \%$ of these having a standard deviation score (SDS) for height below $-2^{6,7)}$. Birth length has been shown to be the single most important predictor for adult height $(\mathrm{AH})$, but birth weight also seems to be an important predictor ${ }^{8)}$. For subjects with a low birth weight, the odds ratio for adult short stature was $1.7^{9)}$.

The aim of this study was to evaluate age at menarche and AH in girls born SGA. We also investigated factors that were associated with the $\mathrm{AH}$.

\section{Materials and methods}

II Tae Hwang, MD, PhD

Department of Pediatrics, Hallym University Kangdong Sacred Heart Hospital, 150 Seongan-ro, Gangdong-gu, Seoul 134-701, Korea

Tel: +82-2-2224-2251

Fax: +82-2-482-8334

E-mail: ithwang83@hallym.or.kr

\section{Patients}

Participants born SGA from 1988 through 1999 were recruited based on hospital chart reviews. Subjects were included whose gestational age was more than 35 weeks and who had a birth weight below the 10th percentile for gestational age. Girls with congenital anomalies, developmental delays, endocrinological problems or a history of growth hormone treatment 
were excluded. Thirty girls were included in the study. They were asked to recall their age at menarche, and their birth histories were obtained from medical records.

\section{Methods}

The subject's heights were measured using a Harpenden stadiometer (Holtain Ltd., Crosswell, UK) accurate to the nearest $0.1 \mathrm{~cm}$.

The AH of subjects whose bone age was over 14 years (19 girls) was the height when the bone age was measured. The $\mathrm{AH}$ of subjects whose bone age was below 14 years (7 girls) was estimated with the Bayley-Pinneau method ${ }^{10)}$.

The bone age was assessed to determine the $\mathrm{AH}$ and interpreted by one investigator using the Greulich and Pyle method $^{11)}$. Midparental height (MPH) was calculated using the following formula: (mother's height + father's height $) \div 2-$ $6.5 \mathrm{~cm}$. The SDSs for birth weight were calculated using a birth weight distribution chart based on national birth certificate data $^{12)}$, assuming that the birth weight follows a normal

\section{Table 1. Clinical characteristics of 30 SGA children}

\begin{tabular}{lc}
\hline Characteristic & Mean \pm SD \\
\hline Gestational age (wk) & $38.4 \pm 1.4$ \\
Birth weight (g) & $2,293 \pm 363$ \\
Mother's height (cm) & $157.8 \pm 4.9$ \\
Mother's height SDS & $-0.6 \pm 1.1$ \\
Father's height (cm) & $172.2 \pm 4.9$ \\
Father's height SDS & $-0.2 \pm 0.9$ \\
Midparental height (cm) & $158.8 \pm 3.3$ \\
Midparental height SDS (cm) & $-0.5 \pm 0.7$ \\
Menarche age $(\mathrm{yr})$ & $11.8 \pm 1.2$ \\
Adult height $(\mathrm{cm}, \mathrm{n}=26)$ & $156.7 \pm 4.8$ \\
Adult height SDS $(\mathrm{n}=26)$ & $-0.8 \pm 1.0$
\end{tabular}

SGA, small for gestational age; SD, standard deviation; SDS, standard deviation score. distribution at each gestational age interval. The SDSs for the heights of the subjects and their parents were calculated using the 2007 growth reference for Korean children and adolescents by the Korean Pediatric Society and the Korea Centers for Disease Control and Prevention ${ }^{13}$. Differences between the AH SDSs and the MPH SDSs were calculated to evaluate the height achievement of the subjects.

\section{Statistics}

The continuous variables were expressed as mean \pm standard deviation for normally distributed variables. The height achievement was evaluated using a paired sample $t$ test. Variables that were not normally distributed according to the Kolmogorov-Smirnov test (age at menarche) were expressed as means and interquartile ranges, and the Wilcoxon signed-rank test was used to compare the differences. Pearson correlation test was used to determine the association between the variables. Multiple linear regression using the enter procedure was performed to examine the factors that affected the height outcome.

The data were analyzed using SPSS ver. 15.0 (SPSS Inc., Chicago, IL, USA). A $P$-value $<0.05$ was used as the cutoff for statistical significance.

\section{Results}

The clinical characteristics of the subjects in this study are shown in Table 1. Their mean gestational age was 38.4 weeks, and their mean birth weight was 2,293 g. The mother's height was significantly lower than the population mean $(P=0.005)$. Father's height was slightly lower, but no statistical difference was observed $(P=0.20)$. The SDS of the AH was significantly lower than the population average ( $P=0.03$, one-sample $t$ test $)$ and was tended to be slightly lower than that of MPH. However,

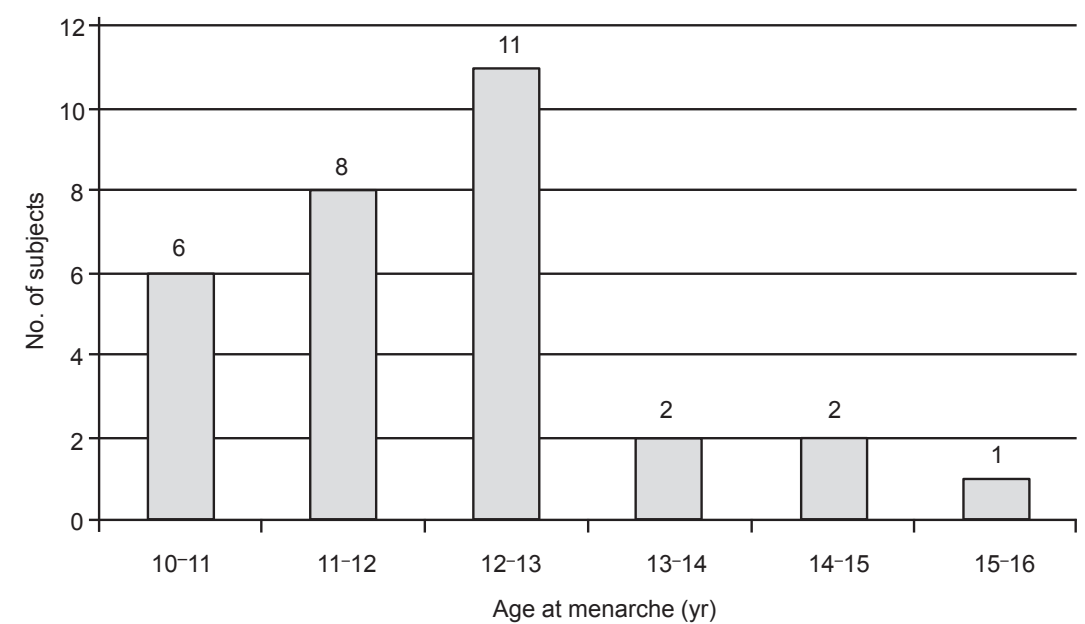

Fig. 1. Distribution of the ages at menarche of the girls born small for gestational age. The mean age at menarche was $11.8 \pm 1.2$ years. 
statistical significance was not observed $(P=0.06$, paired samples $t$ test). Only two girls had an AH SDS below -2 (6.7\%). The age at menarche was $11.8 \pm 1.2$ years (Fig. 1). There was no correlation between birthweight and the age at menarche (Fig. 2).

The difference in the SDSs between the AH and the MPH was measured to evaluate the degree of growth potential that the subjects had reached (Fig. 3). The results showed a positive correlation between the birth weight SDS and the degree of growth potential reached $(P=0.02$, Pearson correlation test).

Multivariate analysis was used to examine the clinical profiles related to birth status and growth. The AH in the subjects born SGA was significantly correlated with the SDS of birth weight for gestational age after adjusting for the MPH SDS and the age at menarche (Table 2).

\section{Discussion}

The aim of this study was to evaluate the association between birth characteristics based on birth weight for gestational age, timing of menarche and growth outcomes. The results demonstrate that the $\mathrm{AH}$ in girls born SGA was significantly

Table 2. Multiple regression analysis of the adult height

\begin{tabular}{lccc}
\hline Variable & $\beta$ coefficient (standardized) & $95 \% \mathrm{Cl}$ & $\rho$-value \\
\hline Birth weight SDS & 0.43 & $0.09-6.49$ & 0.04 \\
$\begin{array}{l}\text { Midparental } \\
\text { height SDS }\end{array}$ & 0.14 & $-2.00-4.04$ & 0.49 \\
Age at menarche & 0.19 & $-0.91-2.47$ & 0.35 \\
$R$ & 0.44 & & \\
\hline Cl, confidence interval. SDS, standard deviation score. &
\end{tabular}

$\mathrm{Cl}$, confidence interval; SDS, standard deviation score.

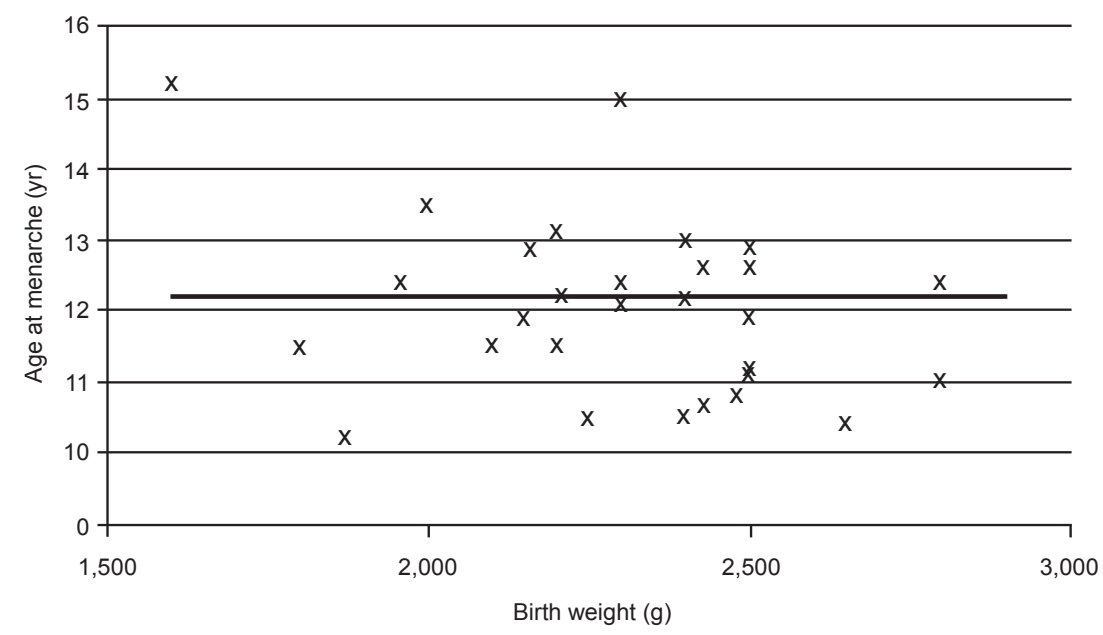

Fig. 2. Birth weights versus the ages at menarche of the girls born small for gestational age. There was no correlation between these two parameters $(P=0.099)$.

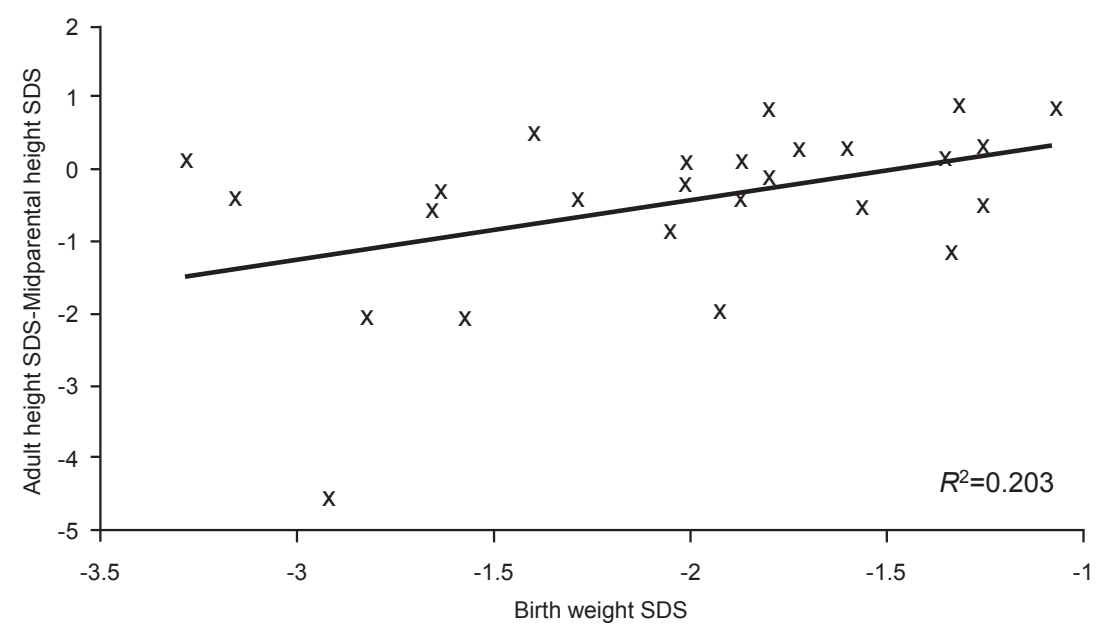

Fig. 3. Birth weight standard deviation score (SDS) compared with the degree of growth potential reached. There was a positive correlation between these two parameters. 
lower than the normal AH and slightly shorter than their target height. The AH was associated with the birth weight for gestational age. The age at menarche was not different compared with the menarche timing of the general population.

The prenatal environment is known to influence the timing of menarche indirectly through postnatal growth. Some studies have investigated the association between SGA and the timing of menarche. Dos Santos Silva et al. ${ }^{4)}$ demonstrated that growth during early childhood was an important determinant of the timing of menarche and that birth weight affected postnatal growth. In a longitudinal follow-up study of an urban Indian cohort, menarche occurred 12 months earlier in the SGA group $^{14)}$. Another study also reported that SGA girls began puberty slightly earlier and were younger at menarche ${ }^{15)}$. In a study of Spanish girls, Ibanez et al. ${ }^{16)}$ reported that lower birth weight contributed to younger age at menarche, with menarche commencing 8-10 months earlier. In Catalonian girls with early onset of puberty, menarche occurred 1.6 years earlier in low birth weight $(<1.5 \mathrm{SD})$ girls and their final height $(\mathrm{FH})$ was 5 $\mathrm{cm}$ shorter than girls whose birth weight was greater than 1.5 $\mathrm{SD}^{17)}$. In a cohort of $45 \mathrm{SGA}$ girls compared with 31 appropriate for gestational age (AGA) girls, Lazar et al. ${ }^{18)}$, reported that menarche was significantly earlier in the SGA group compared with the AGA group $(12.6 \pm 1.6$ vs. $13 \pm 1.4 ; P<0.01)$. The earliest age at menarche was seen in girls with the lowest birth weight and the highest body mass index at 12.5 years (range, 9.4 to 14.4 years) in a study of Western Australian girls ${ }^{19)}$. In contrast, several other reports did not demonstrate that girls born SGA had earlier onset of menarche ${ }^{20-22)}$. In the present study, the age at menarche of girls born SGA was not significantly different from that reported in recent study ${ }^{23)}$ with subjects with similar dates of birth to the participants in the current study $(P=0.861)$.

Several reports demonstrated lower AH in subjects born SGA. Catch-up growth was not achieved in $6.7 \%$ of subjects. This is comparable to a previous study that reported that $6.4 \%$ and $10.3 \%$ of subjects born full-term SGA had not achieved catch-up growth by the time they were 18 years ${ }^{6}$ and 22 years ${ }^{7)}$, respectively. Interestingly, the latter study reported that the mothers and the fathers in the SGA group were significantly shorter than in the non-SGA group. It is known that most catch-up growth in SGA infants occurs in early life, with the most critical time being the first 2 years ${ }^{5,6,8}$. Birth length and target height are important factors in catch-up growth ${ }^{24)}$. In studies, parental height predicted the catch-up growth and the subsequent $\mathrm{AH}^{7,24,25)}$. Although the present study observed no association between the parental height and the catch-up height of the subjects, the maternal height was significantly lower than the population mean. In addition, lower birth weight SDS was significantly correlated with a shorter FH. Maternal height seems to be an important factor in fetal growth and a potential confounder in studies of subjects with SGA. Fetal restriction by uterine size and the subsequent biochemical response of the fetus may play a partial role in postnatal growth catch-up.

There have been several clinical trials aimed at improving the FH in subjects born SGA. One randomized controlled study demonstrated that the FH SDS of SGA subjects without growth hormone deficiency during puberty who received growth hormone treatment increased by a mean of $0.6^{26)}$. Another randomized, double-blind, dose-response trial of short children born SGA without signs of persistent catch-up growth reported that long-term continuous growth hormone treatment normalized their $\mathrm{FH}^{27)}$. Moreover, the improvement in the heights of the children was not significantly different at different growth hormone dosages.

There are several limitations of this study. The mean gestational age of the subjects was lower than the full term. Possible confounders, such as the mother's age at menarche or socioeconomic status were not considered in this analysis. Selection bias and the lack of a control group complicate the interpretation of these results. Studies have reported that the age at menarche is showing downward trend ${ }^{28,29)}$. The relatively small number of subjects in the current study with a wide range of birth dates means we could not detect this trend. Variables associated with catch-up growth in early life after birth could not be included because of limited data.

In the SGA patients, the birth weight SDS seemed to play an important role in the attainment of their target height. More attention may need to be paid to SGA patients whose birth weight is lower for their gestational age than other SGA subjects. Further study using a stratified approach and an age-matched control group may be useful to identify the growth pattern in children born SGA and its effects on other complications related to the intrauterine environment or birth conditions.

\section{Conflict of interest}

No potential conflict of interest relevant to this article was reported.

\section{References}

1. Gardosi J. New definition of small for gestational age based on fetal growth potential. Horm Res 2006;65 Suppl 3:15-8.

2. Persson I, Ahlsson F, Ewald U, Tuvemo T, Qingyuan M, von Rosen D, et al. Influence of perinatal factors on the onset of puberty in boys and girls: implications for interpretation of link with risk of long term diseases. Am J Epidemiol 1999;150:747-55.

3. Adair LS. Size at birth predicts age at menarche. Pediatrics 2001;107:E59.

4. dos Santos Silva I, De Stavola BL, Mann V, Kuh D, Hardy R, Wadsworth ME. Prenatal factors, childhood growth trajectories and age at menarche. Int J Epidemiol 2002;31:405-12

5. Albertsson-Wikland K, Wennergren G, Wennergren M, Vilbergsson G, Rosberg S. Longitudinal follow-up of growth in children born small for gestational age. Acta Paediatr 1993;82:438-43.

6. Karlberg J, Albertsson-Wikland K. Growth in full-term 
small-for-gestational-age infants: from birth to final height. Pediatr Res 1995;38:733-9.

7. Jaquet D, Collin D, Levy-Marchal C, Czernichow P. Adult height distribution in subjects born small for gestational age. Horm Res 2004;62:92-6.

8. Hokken-Koelega AC, De Ridder MA, Lemmen RJ, Den Hartog H, De Muinck Keizer-Schrama SM, Drop SL. Children born small for gestational age: do they catch up? Pediatr Res 1995;38:267-71.

9. Tuvemo T, Cnattingius S, Jonsson B. Prediction of male adult stature using anthropometric data at birth: a nationwide population-based study. Pediatr Res 1999;46:491-5.

10. Bayley N, Pinneau SR. Tables for predicting adult height from skeletal age: revised for use with the Greulich-Pyle hand standards. J Pediatr 1952;40:423-41.

11. Greulich WW, Pyle SI. Radiographic atlas of skeletal development of the hand and wrist. 2nd ed. Stanford: Stanford University Press, 1959.

12. Lee JJ. Birth weight for gestational age patterns by sex, plurality, and parity in Korean population. Korean J Pediatr 2007;50:732-9.

13. Korea Centers for Disease Control and Prevention (KCDC); Korean Pediatric Society, Committee for the Development of Growth Standard for Korean Children and Adolescents. 2007 Korean children and adolescents growth standard: commentary for the development of 2007 growth chart [Internet]. Cheongwon: KCDC, Division of Chronic Disease Surveillance; c2012 [cited 2012 Aug 25]. Available from: http://www.cdc.go.kr/ CDC/info/CdcKrInfo0201.jsp?menuIds=HOME001MNU0004-MNU0007-MNU0025\&fid=28\&q_type=\&q_ value $=\&$ cid $=1235 \&$ pageNum $=74$.

14. Bhargava SK, Ramji S, Srivastava U, Sachdev HP, Kapani V, Datta V, et al. Growth and sexual maturation of low birth weight children: a 14 year follow up. Indian Pediatr 1995;32:963-70.

15. Ghirri P, Bernardini M, Vuerich M, Cuttano AM, Coccoli L, Merusi I, et al. Adrenarche, pubertal development, age at menarche and final height of full-term, born small for gestational age (SGA) girls. Gynecol Endocrinol 2001;15:91-7.

16. Ibanez L, Jimenez R, de Zegher F. Early puberty-menarche after precocious pubarche: relation to prenatal growth. Pediatrics 2006;117:117-21.

17. Ibáñez L, Ferrer A, Marcos MV, Hierro FR, de Zegher F. Early puberty: rapid progression and reduced final height in girls with low birth weight. Pediatrics 2000;106:E72.
18. Lazar L, Pollak U, Kalter-Leibovici O, Pertzelan A, Phillip M. Pubertal course of persistently short children born small for gestational age (SGA) compared with idiopathic short children born appropriate for gestational age (AGA). Eur J Endocrinol 2003;149:425-32.

19. Sloboda DM, Hart R, Doherty DA, Pennell CE, Hickey $\mathrm{M}$. Age at menarche: Influences of prenatal and postnatal growth. J Clin Endocrinol Metab 2007;92:46-50.

20. Veening MA, van Weissenbruch MM, Roord JJ, de Delemarre-van Waal HA. Pubertal development in children born small for gestational age. J Pediatr Endocrinol Metab 2004; 17:1497-505.

21. Albertsson-Wikland K, Karlberg J. Natural growth in children born small for gestational age with and without catch-up growth. Acta Paediatr Suppl 1994;399:64-70.

22. Jaquet D, Leger J, Chevenne D, Czernichow P, Levy-Marchal C. Intrauterine growth retardation predisposes to insulin resistance but not to hyperandrogenism in young women. J Clin Endocrinol Metab 1999;84:3945-9.

23. Park MJ, Lee IS, Shin EK, Joung H, Cho SI. The timing of sexual maturation and secular trends of menarchial age in Korean adolescents. Korean J Pediatr 2006;49:610-6.

24. Luo ZC, Albertsson-Wikland K, Karlberg J. Length and body mass index at birth and target height influences on patterns of postnatal growth in children born small for gestational age. Pediatrics 1998;102:E72.

25. Leger J, Limoni C, Collin D, Czernichow P. Prediction factors in the determination of final height in subjects born small for gestational age. Pediatr Res 1998;43:808-12.

26. Carel JC, Chatelain P, Rochiccioli P, Chaussain JL. Improvement in adult height after growth hormone treatment in adolescents with short stature born small for gestational age: results of a randomized controlled study. J Clin Endocrinol Metab 2003;88:1587-93.

27. Van Pareren Y, Mulder P, Houdijk M, Jansen M, Reeser M, Hokken-Koelega A. Adult height after long-term, continuous growth hormone $(\mathrm{GH})$ treatment in short children born small for gestational age: results of a randomized, double-blind, dose-response GH trial. J Clin Endocrinol Metab 2003;88:3584-90.

28. Cho GJ, Park HT, Shin JH, Hur JY, Kim YT, Kim SH, et al. Age at menarche in a Korean population: secular trends and influencing factors. Eur J Pediatr 2010;169:89-94.

29. Rigon F, Bianchin L, Bernasconi S, Bona G, Bozzola M, Buzi F, et al. Update on age at menarche in Italy: toward the leveling off of the secular trend. J Adolesc Health 2010;46:238-44. 